\title{
Cardiac tumours simulating collagen vascular disease
}

\author{
A P FITZPATRICK, J G LANHAM, D V DOYLE \\ From the National Heart Hospital and Whipps Cross Hospital, London
}

SUMMARY Cardiac tumours can mimic collagen vascular disease and they are often accompanied by profound systemic upset. Both benign and malignant tumours may present in this way. Three cases of cardiac tumour, two malignant and one benign, are reported with just such a presentation. A review of fifteen similar case reports showed that a spectrum of different collagen vascular diseases was diagnosed and treated before the true diagnosis emerged. In half of these cases the cardiac tumour was only diagnosed at necropsy. The diagnosis of collagen vascular disease should not be made in the absence of corroborative laboratory data. In cases of malignant cardiac tumour, and less commonly with atrial myxoma, $\mathbf{M}$ mode and cross sectional echocardiography may not exclude the diagnosis. There may be a good response to steroid treatment in cases of suspected but not confirmed collagen vascular disease in which the true diagnosis is cardiac tumour.

The early diagnosis of cardiac tumours is important because most are benign and may be amenable to curative resection. Fifty per cent are myxomas, commonly in the left atrium, and the rest are a wide variety of different histological types, benign and malignant. Initial misdiagnosis is common, and it was only as recently as 1951 that the first myxoma was correctly diagnosed and successfully treated. ${ }^{1}$

Cardiac tumours may present in three ways. Symptoms may be due to haemodynamic effects, embolic events, or systemic upset. ${ }^{2}$ Left atrial myxomas are often attached by a pedicle to the atrial wall in the region of the fossa ovalis and may interfere with the function of the mitral valve, and occasionally they have been discovered at operation for mitral stenosis. Myxomas are friable and gelatinous and readily fragment giving rise to microemboli and macroemboli; indeed cardiac myxomas have been diagnosed on several occasions after arterial embolectomy. ${ }^{3}$ Finally, in a number of cases constitutional upset dominates the clinical presentation. In some of these patients a collagen vascular disease is diagnosed and they are treated with corticosteroids. We describe three such cases; in each case inappropriate treatment was started and correct diagnosis delayed. We have reviewed fifteen similar patients and discuss some principles in the diagnosis and management.

Requests for reprints to Dr A P Fitzpatrick, St Stephen's Hospital, Fulham Road, London SW10 9TH.

Accepted for publication 21 February 1986

\section{Case reports}

CASE 1

A 32 year old woman presented in the twentieth week of pregnancy with right sided chest pain and exertional dyspnoea. She gave a history of transient erythematous rashes, fleeting arthralgia, and Raynaud's phenomenon. Initial examination showed no abnormality but symptoms persisted and 12 weeks later she developed ankle oedema and tender hepatomegaly. Cardiac auscultation was normal but the jugular venous pulse was increased by $4 \mathrm{~cm}$. There was normochromic, normocytic anaemia, a normal white blood cell count, and thrombocytopenia of $80 \times 10^{9}$ l. The erythrocyte sedimentation rate was $93 \mathrm{~mm} / \mathrm{h}$. The serum albumin concentration was $25 \mathrm{~g} / 1$ and globulin fraction $31 \mathrm{~g} / 1$. Proteinuria was noted. An electrocardiogram showed small voltage QRS complexes and flattened $T$ waves in the precordial leads. An echocardiogram showed a pericardial effusion but no other abnormality.

A diagnosis of systemic lupus erythematosus was made on the basis of her history and the pericarditis, anaemia, thrombocytopenia, and presumed nephritis. Her condition deteriorated and she was treated with intravenous methylprednisolone, followed by oral prednisolone. Pericardiocentesis removed 2.5 1 of blood stained fluid, and culture and cytological examination were negative. Steroid treatment was continued and her erythrocyte sedimentation rate fell to $30 \mathrm{~mm} / \mathrm{h}$ and the haemoglobin concentration rose from $9 \cdot 8 \mathrm{~g} / 1$ to $12 \mathrm{~g} / 1$. The raised jugular venous 
pressure persisted despite pericardiocentesis and an isotope lung scan was performed. This suggested multiple pulmonary emboli and the patient was anticoagulated.

A search for antibodies to nuclear antigens (ANA), extractable nuclear antigens (ENA), and DNA proved negative, raising doubts about the diagnosis. Moreover, 24 hour urinary protein excretion was only $150 \mathrm{mg}$. A total of six M mode and cross sectional echocardiograms were performed, but only the last of these showed the presence of a mass in the right atrium. A computed tomographic scan of the heart and mediastinum confirmed this finding.

An exploratory thoracotomy showed an extensive infiltrating mass within the pericardium. No attempt was made to remove the tumour. Two days after the operation the patient delivered a 28 week old fetus which survived, but the patient died shortly afterwards. Necropsy showed that the right atrium and part of the great vessels were encased in solid tumour. Histological examination of the tumour indicated that it was a pleomorphic rhabdomyosarcoma. There was no evidence of metastatic spread.

\section{CASE 2}

A 23 year old woman presented with a left hemiparesis and a history of five previous episodes of transient left sided weakness associated with headache. Computed tomography suggested cerebral infarction in the region of the basal ganglia. A month later she developed recurrent haemoptyses and pleuritic chest pain. Clinical examination and chest radiography showed a left pleural effusion. A ventilation-perfusion isotope lung scan indicated a pulmonary embolus and she was anticoagulated.

Despite treatment she continued to have headaches and episodes of transient loss of vision. She complained of migratory joint pains and weight loss with persistent fever, and normocytic normochromic anaemia developed. Tests of renal and hepatic function remained normal but tender hepatomegaly and proteinuria were detected. Carotid angiography showed occlusion of the right internal carotid artery. Pulmonary angiography was normal. $M$ mode and cross sectional echocardiography failed to show any abnormality. Systemic vasculitis was diagnosed and she was treated with prednisolone, azathioprine and cyclophosphamide for six weeks.

Ten months after her initial presentation a further echocardiogram was obtained because she had developed a soft third heart sound and a short diastolic murmur. This showed a left atrial mass. Thoracotomy was undertaken and an invasive left atrial angiosarcoma was discovered. The patient died during the operation.
CASE 3

A 40 year old woman presented with malaise, recurrent headache, and visual disturbance. Migraine was diagnosed but both propranolol and clonidine were ineffective as prophylaxis. She developed pain and stiffness in the legs which were accentuated by exercise. There were episodes of regular palpitation but no other cardiovascular symptoms.

General physical examination showed no abnormality. The erythrocyte sedimentation rate was 65 $\mathrm{mm} / \mathrm{h}$, and plasma creatine kinase concentration was grossly raised (1000 units/1). Electromyography showed a slight excess of polyphasic action potentials. A skeletal muscle biopsy specimen showed some type II fibre atrophy but no evidence of inflammation. Nevertheless, the clinical picture was thought to support a diagnosis of polymyositis and treatment with oral corticosteroids was started. Despite this, her symptoms persisted and when she was followed up six months later there was an unexplained sinus tachycardia. A cross sectional echocardiogram was performed which showed a tumour in the left atrium. A benign myxoma was subsequently resected and the patient made a complete recovery.

\section{Discussion}

Patients with cardiac tumours may have no cardiovascular symptoms or signs but there can be prominent systemic disturbance. The clinical picture may include fever, weight loss, and anaemia, and often there will be a raised erythrocyte sedimentation rate and serum globulin concentrations. Constitutional features often accompany cardiovascular disturbances. Sometimes the absence of the latter may lead to an initial misdiagnosis of collagen vascular disease. There are two reasons for this. Firstly, the clinical diagnosis of systemic vasculitis is not infrequently based on non-specific criteria. After the exclusion of other causes of multisystem disease, for example infection and sarcoidosis, it may sometimes be necessary to institute treatment for vasculitis in the severely ill patient with an undiagnosed disorder, before histological confirmation can be obtained. Vasculitis can be difficult to prove, however, if the tissues affected are not amenable to biopsy.

Other clinical features that lead to the mistaken diagnosis of connective tissue disease or vasculitis in patients with cardiac tumours include Raynaud's phenomenon, rash, pericarditis, and arthritis. In the context of a multisystem illness such features strongly suggest a collagen vascular disease. Table 1 lists clinical features and their prominence in fifteen cases that were similar to the three we have reported above. 
Table 1 Clinical features and laboratory findings reported in 15 patients with cardiac tumours simulating collagen vascular disease

\begin{tabular}{ll||cc}
\hline No of cases & Clinical feature & No of cases & Laboratory findings \\
\hline 10 & Arthritis/arthralgia & $15(15)$ & Raised erythrocyte sedimentation rate \\
8 & Stroke/transient ischaemic attack & $5(12)$ & Anaemia \\
7 & Cardiac murmur & $3(6)$ & Raised $\gamma$ globulins \\
7 & Rash & $3(7)$ & Raised $\alpha_{2}$ globulins \\
6 & Fever & $0(3)$ & Lupus erythematosus cells \\
6 & Weight loss & $1(9)$ & Antinuclear antibody \\
5 & Myalgia & $0(7)$ & Rheumatoid factor \\
5 & Chest pain & $1(3)$ & Cryoglobulins \\
4 & Raynaud's phenomenon & $-(2)$ & Complement abnormalities \\
2 & Pericarditis & $1(1)$ & Anti-heart muscle antibodies \\
1 & Epilepsy & & \\
1 & Headache & &
\end{tabular}

*Numbers in parentheses are number of cases in which test was performed.

Table 2 Diagnosis, treatment, and outcome in 15 patients with primary tumours initially misdiagnosed as collagen vascular disease

\begin{tabular}{|c|c|c|c|c|c|c|c|}
\hline Case & Age & Sex & Initial diagnosis & Treatment given & Final diagnosis & Outcome & Reference \\
\hline $\begin{array}{r}1 \\
2 \\
3 \\
4 \\
5 \\
6 \\
7 \\
8 \\
9 \\
10 \\
11 \\
12 \\
13 \\
14 \\
15\end{array}$ & $\begin{array}{r}56 \\
38 \\
38 \\
19 \\
14 \\
26 \\
67 \\
42 \\
15 \\
16 \\
31 \\
9 \\
42 \\
39 \\
46\end{array}$ & $\begin{array}{l}\mathrm{M} \\
\mathrm{F} \\
\mathrm{M} \\
\mathrm{M} \\
\mathrm{M} \\
\mathrm{M} \\
\mathrm{F} \\
\mathrm{F} \\
\mathrm{F} \\
\mathrm{M} \\
\mathrm{F} \\
\mathrm{F} \\
\mathrm{F} \\
\mathrm{M} \\
\mathrm{M}\end{array}$ & $\begin{array}{l}\text { Collagen disease } \\
\text { Rheumatoid arthritis } \\
\text { Vasculitis } \\
\text { Polyarteritis nodosum } \\
\text { Collagen disease } \\
\text { Polyarteritis nodosum } \\
\text { Rheumatoid arthritis } \\
\text { Vasculitis } \\
\text { Collagen disease } \\
\text { Collagen disease } \\
\text { Wegener's granulomatosis } \\
\text { Dermatomyositis } \\
\text { Collagen disease } \\
\text { Vasculitis } \\
\text { Collagen disease }\end{array}$ & 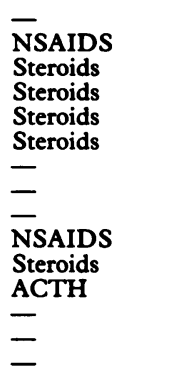 & $\begin{array}{l}\text { Myxoma (n) } \\
\text { Myxoma (o) } \\
\text { Myxoma (o) } \\
\text { Myxoma (o) } \\
\text { Myxoma (o) } \\
\text { Myxoma (o) } \\
\text { Myxoma (n) } \\
\text { Myxoma (o) } \\
\text { Myxoma (o) } \\
\text { Lymphoma (n) } \\
\text { Myxoma (n) } \\
\text { Myxoma (n) } \\
\text { Myxoma (n) } \\
\text { Myxoma (n) } \\
\text { Myxoma (n) }\end{array}$ & $\begin{array}{l}\text { Died } \\
\text { Survived } \\
\text { Survived } \\
\text { Survived } \\
\text { Survived } \\
\text { Survived } \\
\text { Died } \\
\text { Survived } \\
\text { Survived } \\
\text { Died } \\
\text { Died } \\
\text { Died } \\
\text { Died } \\
\text { Died } \\
\text { Died }\end{array}$ & $\begin{array}{r}4 \\
13 \\
5 \\
10 \\
6 \\
11 \\
14 \\
12 \\
7 \\
8 \\
16 \\
15 \\
9 \\
9 \\
9\end{array}$ \\
\hline
\end{tabular}

o, operative specimen; $n$, necropsy specimen; NSAIDS, non-steroidal anti-inflammatory drugs; ACTH, adrenocorticotropic hormone.

When clinical features in patients with occult cardiac neoplasms suggest collagen vascular disease, laboratory findings seldom support the diagnosis. Table 1 lists some of these. Non-specific abnormalities, such as a raised erythrocyte sedimentation rate, anaemia, and raised serum globulin concentrations, are common.

Only one patient had a positive antinuclear antibody test (with a titre of $1 / 64^{8}$ ), however, and tests for lupus erythematosus cells, rheumatoid factor, and complement depletion were consistently normal. The absence of supporting laboratory evidence should always cast doubt on the diagnosis of connective tissue disease or vasculitis. There has been considerable interest in the clinical entity "antinuclear antibody-negative lupus" but in such suspected cases antibodies to Ro and $\mathrm{La}$ antigens ("SS-A and SS-B"- - antibodies commonly present in Sjögren's syndrome) should always be sought and may help to establish the diagnosis. ${ }^{17}$

Table 2 summarises fifteen similar cases of cardiac tumour simulating collagen vascular disease. With the exception of a single case of lymphoma all were benign myxomas. Cases 1 and 2 reported above, however, indicate that despite quite distinct histopathological features, malignant primary cardiac neoplasms may present in a similar way. Myxomas tend to friable, gelatinous tumours and some of their constitutional effects may be explained by microembolic events. Nevertheless, if solid, sessile, malignant tumours have similar clinical presentations, some other pathogenesis must exist, presumably immunological.

Immunological mechanisms have been suggested, and antibodies to cardiac muscle have been sought and found in a single case, ${ }^{13}$ although the significance of this in isolation is unknown.

Detection of these tumours at an early state is important. Table 2 shows that of fourteen previously reported cases of myxoma, initially diagnosed as collagen vascular disease, eight died and the correct diagnosis only came to light at necropsy.

With malignant cardiac tumours early detection is important. Despite their proximity to the circulation such tumours tend to be confined to the heart until relatively late in their course. There have been cases 
of successful cardiac transplantation for primary cardiac tumours. ${ }^{18}$

In patients with a non-infective multisystem disease in which serological and autoimmune testing are negative, a cardiac tumour should be considered. Cross sectional echocardiography will usually detect myxomas cheaply, reliably, and quickly. The absence of an obvious myxoma, however, does not rule out the possiblity of a myocardial neoplasm. As our report shows, repeated false negative results may occur with malignant infiltrating tumours. If the diagnosis is seriously entertained, the tumour may need to be pursued with other investigations, such as computed tomography or nuclear magnetic resonance, despite a normal echocardiogram.

These cases illustrate the importance of considering cardiac neoplasms in the differential diagnosis of multisystem disease. Moreover, they emphasise the need for an intensive search for supporting histological and laboratory data in patients diagnosed as having connective tissue disease or vasculitis.

\section{References}

1 Crafoord C. Panel discussion on the late results of mitral commisurotomy. In: Lam CR, ed. International symposium on cardiovascular surgery. (Studies in Physiology, Diagnosis and Techniques.) (Henry Ford Hospital, Detroit, Michigan.) Philadelphia: WB Saunders, 1955: 202.

2 Goodwin JF. Diagnosis of left atrial myxoma. Lancet 1963; i: 464-7.

3 Sutton M St J, Mercier L-A, Guilliani ER, Lie JT. Atrial myxoma: a review of clinical experience in forty patients. Mayo Clin Proc 1980; 55: 371-6.

4 McGregor GA, Cullen RA. Syndrome of fever, anaemia and high sedimentation rate with an atrial myxoma. $\mathrm{Br}$ Med f 1959; ii: 991-3.

5 Huston KA, Coombs JJ Jr, Lie JT, Gilliani ER. Left atrial myxoma simulating peripheral vasculitis. Mayo Clin Proc 1978; 53: 752-6.

6 Kaminsky ME. Atrial myxomas mimicking a collagen disorder. Chest 1979; 75: 93-5.

7 Skanse B, Berg ND, Westfelt L. Atrial myxoma with Raynaud's phenomenon as the initial problem. Acta Med Scand 1959; 164: 321-4.

8 Scully RE, Mark EJ, McNeely BV. Case records of Massachusetts General Hospital. N Engl f Med 1983; 309: 169-75.

9 Yufe R, Karpati G, Carpenter S. Cardiac myxoma: a diagnostic challenge for the neurologist. Neurology (NY) 1976; 26: 1060-4.

10 Leonhardt ETG, Kullenberg KPG. Bilateral atrial myxomas with multiple arterial aneurysms: a syndrome mimicking polyarteritis nodosum. Am $\mathcal{F}$ Med 1977; 62: 792-4.

11 Thomas $\mathrm{MH}$. Myxoma masquerading as polyarteritis nodosum. F Rheumatol 1981; 8: 133-7.

12 Buchanan RRC, Cairns JC, Kragg S, Robinson JG. Left atrial myxoma mimicking vasculitis: echocardiographic diagnosis. Can Med Assoc $\mathcal{F}$ 1979; 120: 1540-2.

13 Currey HLF, Matthews JA, Robinson J. Right atrial myxoma mimicking a rheumatic disorder. $\mathrm{Br}$ Med $\mathcal{f}$ 1967 ; i: $547-8$.

14 Dixon A St J. Progress in clinical rheumatology. London: Churchill, 1965.

$15 \mathrm{McWhirter}$ WR, Tetteh-Lartey EV. A case of atrial myxoma. Br Heart f 1974; 36: 839-40.

16 Cohen AI, McIntosh HD, Orgain ES. The mimetic nature of left atrial myxomas: report of a case presenting as a severe illness and simulating massive mitral insufficiency at cardiac catheterisation. $A m \mathcal{F}$ Cardiol 1963; 11: 902-7.

17 Hughes GRV. Autoantibodies in lupus and its variants: experience in 1000 patients. $\mathrm{Br} \mathrm{Med} \mathcal{F}$ 1984; 289: 339-42.

18 Jamieson SW, Gaudiani VA, Reitz BA, Oyer PE, Stinson EB, Shumway NE. Operative treatment of an unresectable tumour of the left ventricle. $\mathcal{F}$ Thorac Cardiovasc Surg 1981; 81: 797-99. 